Global Journal of Engineering and Technology Advances

eISSN: 2582-5003

Cross Ref DOI: $10.30574 /$ gjeta

GJETA

Journal homepage: https://gjeta.com/

(REVIEW ARTICLE)

\title{
A review of speed - flow relationships in traffic studies
}

\author{
Ishraq Hameed Naser * \\ Department of Civil Engineering, College of Engineering, Al-Iraqia University, Baghdad, Iraq.
}

Global Journal of Engineering and Technology Advances, 2021, 06(01), 026-035

Publication history: Received on 24 December 2020; revised on 30 December 2020; accepted on 02 January 2021

Article DOI: https://doi.org/10.30574/gjeta.2021.6.1.0122

\begin{abstract}
This paper produce a literature review on speed-flow relationship for urban area and the models which had been adopted to reveals the relationship. The model of the speed-flow relationship is useful in planning, designing and evaluating highway capacity. The three traffic parameters are prescribed. Also, their studies, applications, and modeling are reviewed and explained.
\end{abstract}

Keywords: Speed; Flow; Relation and Modeling.

\section{Introduction}

Roads are usually divided into two main groups, rural roads and urban roads, in traffic studies. Several studies have been performed on urban roads to research the impact of their geometric and traffic parameters on speed [1-13]. Parameters that have similar beneficial effects on traffic speed but with a different degree of importance are the posted speed limit, lane width, and number of lanes [6-10], also, The results of the sort of right turn, time of the day.The volume and composition of traffic and traffic driveways differed in traffic speed [8-13] on the other hand, as there is a very high degree of strategic planning and management of urban transport networks, Decision-makers should apply a systematic approach to a complex problem, backed by different instruments of policy evaluation. These instruments aim to take all of them into account. In order to promote "well-informed" decisions, the relevant factors are relevant. A fairly universal and universal one, Speed-flow curves identify traffic states along the road in the case of road traffic. The so-called volume-delay function (VDF) describes the relation between transport demand and transport demand in a transformed form of this function. Normal on-road travel times. VDF is the basis of models of traffic allocation and Basic calculations, because it basically effects of transport modeling And evaluation [14,15]. The speed flow relationships analysis has become timely in recent years as a vehicle. The fleet improved, the total amount of traffic increased and th e automated fleet increased more comprehensively. It became possible to collect data and developing model [16]. The rationale for the analysis or update is to Improving methods of transport modeling and developing more stable models. Nevertheless, feedback In essence, road traffic is centered and restricted to non-congested states, while the most interesting topic will be congestion modeling. Another factor is that speed-flow curves are usually extracted and validated on the road network used for long-distance, interurban travel, but as the urban population ratio rises, urban transport and its strategic planning are becoming increasingly relevant [17]. However, the theory of traffic flow requires the creation of mathematical relationships among the main elements of a traffic stream; flow, density, and speed. These partnerships assist the traffic engineer to prepare, design and assess the efficacy of the implementation of road system traffic engineering initiatives. On speed-flow relationships, there are few studies in Iraq. Instead of developing detailed continuous relationships for a wide variety of flows, these often describe free flow conditions. In addition, they use traditional approaches that have minimal capabilities. The relationship between traffic speed and flow in the last six decades has been investigated by researchers in several countries. There have been numerous speed-flow relationships established, but they are primarily for uninterrupted flow streams. In the literature on speed-flow relationships of

\footnotetext{
${ }^{*}$ Corresponding author: Ishraq Hameed Naser
}

Department of Civil Engineering, College of Engineering, Al-Iraqia University ntry.

Copyright (C) 2021 Author(s) retain the copyright of this article. This article is published under the terms of the Creative Commons Attribution Liscense 4.0. 
disrupted flow, such as on an arterial path, not much can be found. [18]. The Highway Capacity Manual 1994 (HCM94) offers a recent understanding of the relationship between empirical speed-flow, which shows that for higher flow volumes, this area has a more gradual slope with constant speed. The focus is therefore on transport professionals to concentrate their research efforts on the creation of analytical speed-flow models that can explain the relationship between speed-flow and real actions. [19]. Traffic flow interference causes speeds to be decreased vehicles to drive closer together and density to increase, these caused weather conditions, cross-country traffic, a disabled vehicle, an accident or other marginal conditions can cause interference. Although one or more of these conditions cause further interference, the volume can still be maintained within certain limits, but with a further decrease in speed, closer spacing of vehicles, and greater density. If interference becomes so high that the average speed drops below that needed to sustain steady flow, despite closer vehicle spacing and greater density, and there is a rapid decrease in speed and traffic flow, and extreme congestion sets in. The major factors affecting the speed-flow relationship are traffic composition, free flow velocity, terrain type, road surface conditions, lane width, shoulder width, weather conditions, etc.[20]. For the steady-state relation between space mean velocity $\left(\mathrm{u}_{\mathrm{s}}\right)$, flow $(\mathrm{q})$ and density $(\mathrm{k})$ of traffic, macroscopic traffic flow theories are most suitable. The mean velocity of space $(\mathrm{km} / \mathrm{h})$ gives the mean velocity of vehicles along a stretch of road at the moment in question. Traffic flow "(veh/h)" is the number of vehicles "(per time unit)" that during a time interval, cross a point of the lane. Traffic density (veh/ $\mathrm{km}$ ) is the number of vehicles (per unit length of lane) on an instantaneous segment of the road corresponding to the speed measurement. The fundamental flow relationship relating to traffic flow with space mean velocity and traffic density is shown in Equation (1).
"q $=\mathrm{u}^{*} \mathrm{k} "$
Eq.1

where

"q = flow rate (veh/hr)"

$" u=$ average travel speed $(\mathrm{km} / \mathrm{hr}) "$

" $k=$ average density $(\mathrm{veh} / \mathrm{km}) "$

All the variables are functions of time and space in the equation. A certain section of road and a certain moment in time are related to speed and density. On the other hand, flow is a local variable that is connected to a time interval over which it is important to integrate speed and density. Equations (1) and (2) is true for all forms of traffic flow situations if the variables are correctly calculated.

The standard assumption is that speed is a density function, but because of the spatial existence of the two variables, this relation is difficult to explore. Fortunately, a theoretically accurate approximation of the space mean velocity ( $u$ s) of traffic can be obtained by using the harmonic mean of local velocity observations using Equation (2) [21]

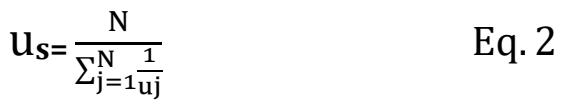

"where $u_{j}$ : - individual vehicles speed and $j=1, \ldots, N$ are the individual vehicles in the data set for the time interval in question."

Local measurements of speed and flow are the standard method for estimating speed flow density relationships and translating the data into average travel speed, flow and density data using equation (2). The interdependencies between speed, flow, and density can be calculated for the traffic flow in question from the transformed data.

In capacity relations, such as between flow, density, and speed, space speeds are used. Space mean velocity is thus the proper measure of a highway's performance, and maps of facility performance should be in terms of space mean speed. Fortunately, space mean speed is related to section travel time and spot speeds, so that such data is also used to estimate space-mean-speed [22]. From the point of view of causation, the relationship of speed-density seems to be most important for drivers who change their speeds according to the density of the traffic around them. In general, the flowdensity relationship is the most useful since it unifies different theoretical ideas and provides relationships for traffic control activities [23]. 


\section{Literature Review}

A systematic literature review in order to set the scope for this article It is being undertaken. The aims of this article are to analyze the previous one Study activities carried out in this area and the use of this knowledge. The show of literature will parted to two section. Firstly, is speed and secondly reveals the flow.

\subsection{Speed}

Speed is defined as a rate of motion, generally in "miles per hour (mph)" or kilometers per hour "(km/hr)" as distance per unit time [24]. In reality, speed is an essential measure of the motorist's standard of traffic service. For several forms of facilities, such as rural two-lane highways, arterials, highway weaving sections, and others, it is used as a significant indicator of effectiveness to determine service levels. The average travel speed is the speed measure used. This measure because it is easily calculated within the traffic stream from the observation of individual vehicles and because it is the most statistically relevant measure in relation to other factors. Speed criteria must recognize driver expectations and the function of the roadway when used as a measure of efficiency. Therefore, on a freeway, a driver expects greater speed than on an urban arterial [25]. Drivers are affected by many variables in the choice of their "speeds", such as "traffic volume", "traffic density", "road condition", "vehicle condition", and "environmental conditions", as well as the limitations of the [26] speed regulations. In traffic various forms of speed calculation are encountered. The following can include: "spot speed, Running speed, Journey (travel) speed.....etc".

The "spot speed" study is designed to measure the "speed characteristics" under the traffic and environmental conditions prevailing at the time of the study, at a given location [27]. For an accurate statistical assessment, a sufficient number of vehicles must have their speeds registered. The aim of such research is to determine the speeds preferred by drivers when unencumbered by traffic congestion. Thus such studies are usually performed under 'free flow (light traffic)' conditions. [28] The time of day to perform a speed analysis depends on the study's intent. In general, when the object of the study is to set "posted speed limits" observe "speed limit" observe "observe speed trends" or collect basic data, it is recommended that the study be carried out when "traffic is free-flowing, usually during off-peak hours" [16]. Average speed, which is the arithmetic average of all vehicle speeds detected, The average spot speed is often referred to as the time mean velocity equation.[29]

$\begin{array}{ll}\overline{\boldsymbol{u}}=\frac{\sum \text { fiui }}{\sum f i} & \\ & \text { Where } \\ u & =\text { arithmetic mean, } \\ f_{i} & =\text { number of observations in the ith speed group, and } \\ u_{i} & =\text { midvalue for the ith speed group. }\end{array}$

The Running Speed and Travel Speed Studies 'Average travel speed and average running speed' are two types of mean space velocity that are commonly used as metrics for traffic engineering. Both are measured as a distance separated by an average time to cross a highway line. The average travel speed is defined by the average travel time, while the average travel speed is determined by the average travel time[30]. The mean travel speed is called "space" since the use of average travel time effectively weighs the average time each vehicle spends in "space" relative to the length of time the mean speed of travel is shown in Equation (4) [24]:

$$
u s=\frac{L}{\sum_{i=1}^{n} \frac{t i}{n}}=\frac{n \mathrm{~L}}{\sum_{i=1}^{n} t i} \quad E q \cdot 4
$$

where:

$\begin{array}{ll}-u_{s} & =\text { average travel speed or space mean speed (mph), } \\ L & =\text { length of the highway segment (miles), } \\ t_{i} & =\text { travel time of the ith vehicle to traverse the section (hours); and } \\ n & =\text { number of travel times observed }\end{array}$




\subsection{Free-Flow Speed}

In speed-flow relationships, the principle of free-flow speed was used to describe the consistency of geometric architecture for a facility [27]. The speed of free-flow is clear as the average speed of traffic in circumstances of low volume and is meant to reflect the rates of travel that vehicles prefer when other traffic is not impeded [28]. The orientation of the route, especially horizontal curves, and the cross-section of the roadway influence the free-flow speed. Speed-flow relationships are represented by a family of parallel curves for various free-flow speeds rather than a single speed-flow relationship in the updated operational analysis protocol. In this context, free-flow speed tends to be more suitable for use than design speed since free flow speed is based on actual operating conditions, while design speed is chosen by a highway agency and may or may not be specifically linked to the actual conditions of service [29]. The freeflow speed of a highway can be calculated directly from a field-based speed survey. No subsequent changes are made to free-flow speed when field measured data is used. Recommended is the field research can be carried out in periods of low traffic flow "(up to two-way flow of $200 \mathrm{pc} / \mathrm{h}$ )" [30]. In general, off-peak hours are good times for Observe low levels of flow. In traffic engineering [32] various forms of speed calculation are encountered. Free flow speeds can be assessed away from the intersections by test vehicles or by spot speed observations.

Due to the impact of vehicle interactions, the average speed of a vehicle in motion along a certain road length, or the running speed, is typically lower than the target speed of its driver. Similarly, the average operating speed of all vehicles in the arterial segment is typically lower than the segment's free flow speed. [29].

\subsection{Speed - flow Relationships}

Free-flow speed is the average speed of motorists across certain portions of arterial segments that are not near to the signposted intersections, as observed under conditions of very low traffic volume, while other vehicles or traffic signals do not limit drivers. The average free-flow speed for the given facility and its usage should approximate the desired speeds of the motorists. Free flow speeds can be measured away from the intersections by test vehicles or by spot speed observations. Numerous studies have confirmed the characteristic shape of the relationship between speed and flow and have shown that the free flow zone is basically a linear relationship. There's little contact between individual vehicles when the flow is very low. Therefore, drivers are free to travel at the maximum speed possible. As the flow tends to zero, the absolute maximum speed is obtained, and it is known as the mean free speed (uf) [35].

Studies evaluating the speed-flow relationship, which forms the basis of urban road analysis and design, are however, minimal. A study conducted in the city of Yogyakarta during peak hours on congested urban roads (with high side friction) showed that the real capacity and speed are higher than the values predicted by Indonesian HCM2. The effects of factors such as street parking, city bus stops, turning vehicles at intersections have also been identified and U-turn cars were higher than the figures recorded in the HCM2 Indonesian [23].

Another Indian study found that there is a difference between the authorized speed range for use in India and the speed ranges specified in HCM20003. A new Level of Service (LOS) range to be extended to urban roads in India has been introduced, which is different from that used in HCM 2000. This disparity was due to the heterogeneous nature of the flow of traffic along with the different geometric features of India's road sections [37].

Casey and Tindall (1966) analyzed their speed-flow data in terms of directional flow for Australian studies. They found that the primary flow has a greater effect on the mean velocity of the primary direction than the opposing flow. They derived the following equation of regression [38]:

$$
\begin{aligned}
& \text { "V1 = 72.6 - 0.0158Q1 - 0.0087Qo" } \ldots \ldots \ldots \ldots \ldots \ldots \ldots \ldots . . . . . . . . . . . . .5 q \\
& \text { "where," }
\end{aligned}
$$

"V1: mean speed for traffic in the primary direction $(\mathrm{km} / \mathrm{h}) . "$

"Q1: primary direction flow (veh/h), Q1 $\leq 1500 \mathrm{veh} / \mathrm{h} "$

"Qo: opposing direction flow (veh/h), Qo $\leq 1300$ veh/h."

In Britain, the technique adopted was to research capability in terms of the relationship between the average vehicle running speed and the flow of traffic [39]. 


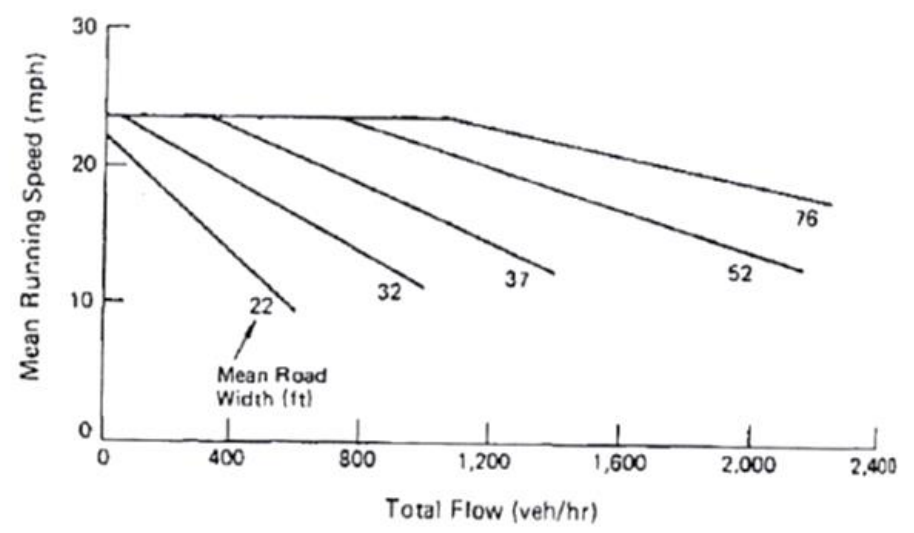

Figure 1 Speed - flow Model Development by British Road Research Laboratory. [39]

Here, for a substantial range of flow that ultimately breaks to a linear decrease in speed with increasing flow, the speed is taken as constant. Road width is a significant parameter here. Wardrop and Charlesworth described how stream speed and flow can be determined by travelling in a vehicle against and with the flow. Duncan proposed that the parabolic or other curved form (as used to define speed -flow relationships) is based on an insufficient understanding of underlying statistical effects. By fitting two very different equations to speed flow data seemingly split randomly at $(70) \mathrm{km} / \mathrm{h}$, he expanded this idea. Although the arbitrary splitting of the data at a fixed point precludes the possibility that the two traffic flow regimes could cross[40].

The HCM-1985 [41] also defined the decrease in speed as a two-way volume feature. The form of the curve is concave; at low volume, the decrease is more steep, but at higher volume of traffic, However, HCM-2000 [31] assumed a linear relationship as shown in Figures 2,3 between speed and flow rate and the following equation:

"ATS = FFS- 0.0125Vp - fnp Eq.6

Where:

"ATS: average travel speed for both directions $(\mathrm{km} / \mathrm{h}) ; "$

"FFS: free-flow speed (km/h);"

"fnp: adjustment for percentage of no-passing zone;"

"Vp: passenger car equivalent flow rate (pc/h)."

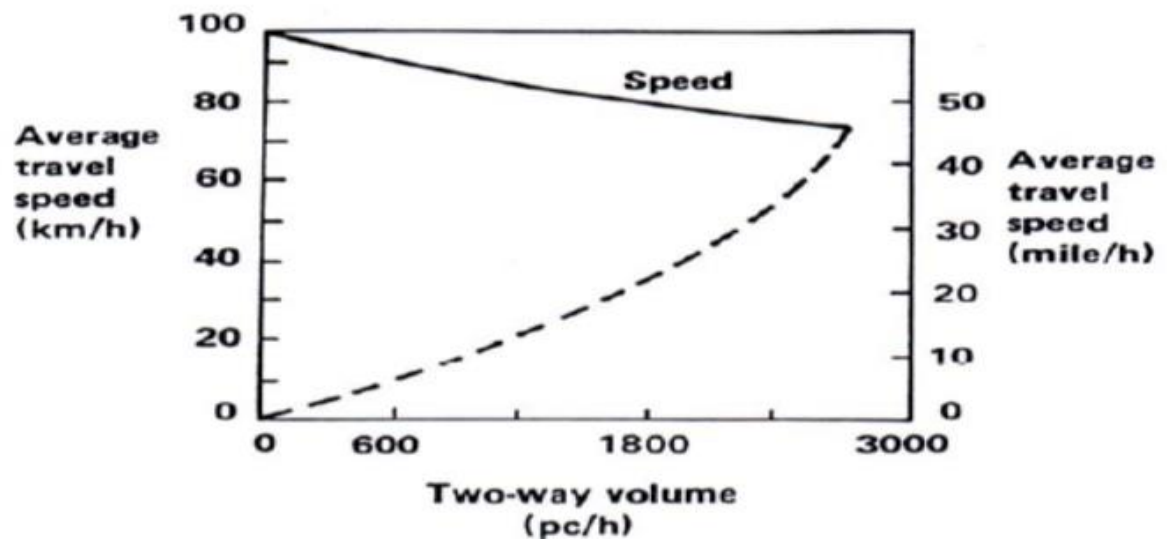

Figure 2 Speed - Flow relationships on Two-Lane Highways [41] 


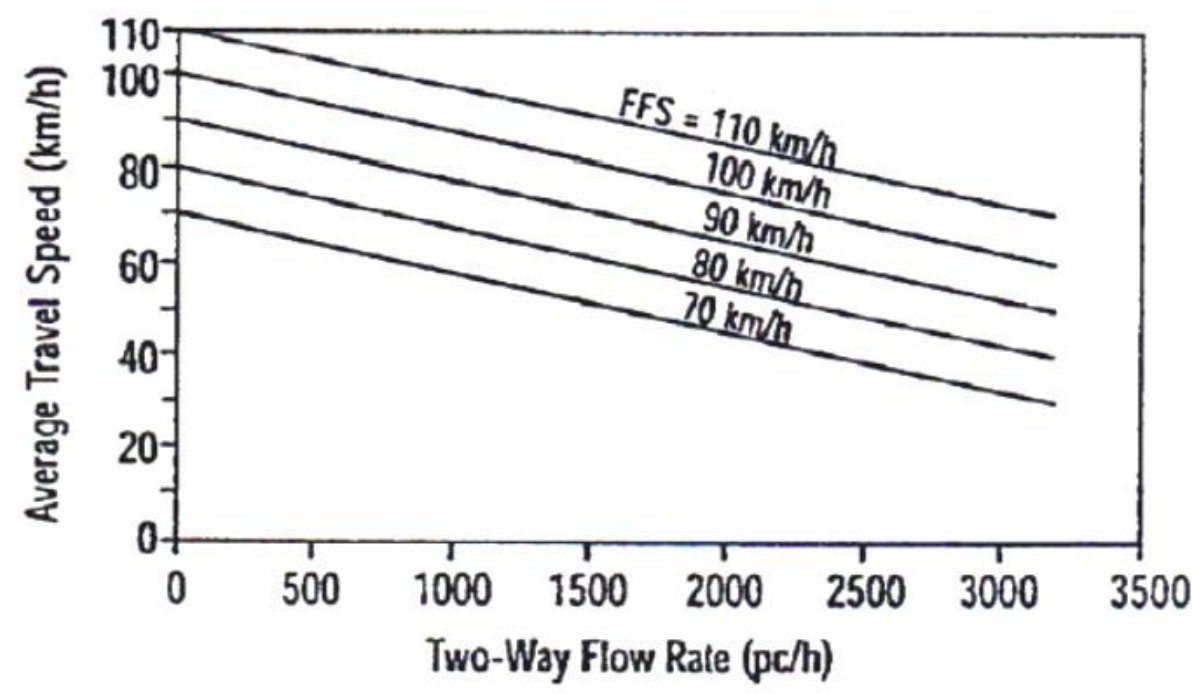

Figure 3 Two-Lane Highways Speed-Flow Relationship [31]

The speed-flow relationship does not necessarily reflect the impact of flow on speed during congested conditions, but also the effect of congestion on flow [42]. The scope for the development of various speed-flow relationship forms is considerable. They are: "Steady - state, Non - steady state and Average conditions.

A steady-state-speed-flow relationship is discovered if the speed of the vehicles in the traffic stream is constant over the distance measured by the speed. However, if the speeds change, then it is important to influence the flow[43].

A linear relationship between flow and speed out to maximum flow, with a curvilinear segment between maximum flow and origin [23] was postulated by some early investigators (e.g. Walker). It is important to use appropriate time intervals in measuring the velocity-flow relationship, as they strongly affect the shape of the curve, particularly around the ability flow and the congested area. For practical purposes, five minute intervals are recommended as the shortest time basis.

By voicing the two-lane traffic stream models, the shared road space essence of two-lane flow was masked in the capacity manuals. Complete flow rather than stream directional flow in terms of a square root function for the estimation of the concave speed flow curve was proposed by Brilon and Weiser [44]. The effect of the opposing flow was suggested using the Erlang model by [45]. The models proposed were:

"SMS =101.7 - 0.2899 Qd - 0.0045Qo (for posted speed $=100 \mathrm{~km} / \mathrm{h}$ )"

"SMS = 87.7 - 0.2335 Qo $-0.0017 \mathrm{Q}$ (for posted speed $=80 \mathrm{~km} / \mathrm{h}$ )"

Where:

"SMS: space mean speed $(\mathrm{km} / \mathrm{h} "$

"Qd: flow rate in the observed direction (veh/h), Qd $\leq 1600$ veh/h".

"Qo: flow rate in the opposed direction (veh/h), Qo 1550 veh/h".

For this model, the effect of the opposing flow was also significantly smaller than the effect of the flow rate in the direction observed. The concave speed-flow model gave the knowledge a slightly better fit than the linear model. Especially at low volumes, the empirical speed flow data appears to be steeper [46], since high free flow velocities are high. However the decrease in speed due to increased flow rate in Finish was smaller Highways than in the HCM-2000 projected. 
Duncan [40] studied the variables influencing the low-flow free-flow) average travel speeds in Britain. He found that in the road testing laboratory (RRL), the free speed of light vehicles is influenced by the total flow for both directions and the average curvature along the Schofield road segment (1986) established an extreme relationship between speed and flow, where a constant speed is obtained at a certain degree of flow, after which a constant speed is obtained with an increase in flow. The speed begins to decrease at a higher level of flow.

Also, For two-lane roads in Indonesia, Bang, et al [47] developed speed flow relationships and simulation model. They find that free speed is significantly lower in Indonesia under ideal conditions than in developed countries.

Hasan [48] studied spot speed characteristics on the rural Erbil-Kirkuk highway in Iraq. By means of a manual stopwatch, he collected data on spot speed and volume using the pavement marking system and compared it with the test car method for speed measurements. From the findings, he concluded that the service level for the Erbil-Kirkuk Highway is D. He also defined that for this highway, the mean spot velocity for mixed traffic is $(91.3 \mathrm{~m} 0.9) \mathrm{km} / \mathrm{h}$.

In the planning, designing and study of highway capability [49], the speed-flow relationship model is useful. Parameters that have been studied in Hong Kong are road width, gradient, speed limit, rainfall, and ramp control [7]. In Singapore, the parameters that have the most influence on the speed-flow relationship for urban roads are intersection density and delay at intersections[18].

Tareq M. Al-Bahr and Othman Che Puan (2017) [50] presented the preliminary findings of the speed-flow relationship on urban roads was discussed. The research was carried out on the basis of a broad variety of geometrical and traffic parameters to establish a speed-flow model for urban roads. They were depending on geometric and traffic parameters In order to investigate the effect of various geometric and traffic parameters on the speed-flow relationship, four urban roads in the state of Johor Bahru were chosen. Sixteen checks, four for each of the roads chosen, were carried out. Geometric parameters, such as lane width, lane numbers, median form, and parameters of traffic, such as access density, cross-section density. In defining the speed-flow relationship, "intersection density, delay at intersection, traffic flow mix" was used. The vehicle test method (VTM) was used to collect traffic data while the geometric data were collected by direct on-site measurement and observation. The results obtained in this study indicated that the speed and crosssectional parameters recorded, such as lane width, lane number and road width, have a major impact on the speed-flow relationship relative to the speed-flow relationship. Finally, they conclude that an important impact on the speed-flow relationship can be predicted from the cross-sectional parameters of urban roads. The speed limit set has a major impact on the relationship between speed flows on urban roads. For the creation of appropriate speed flow models, the parameters considered in this study are necessary.

In Iraq, Samir Shafeek Hashim (2006) presented a method for prediction of speed-flow relationship. He was using neural artificial network model to investigate the study. It incorporates the three key features of traffic flow. The interaction between the main variables, speed, flow, and density for two major types of traffic facilities is represented in this model. At that time, neural networks at traffic stream was using in Iraq for the first time. The input to the model is density and the outputs are speed and flow. The study concluded that The Neural Network method can be successfully used to predict traffic speed with a high degree of precision, as the results of the T-test show that there is no substantial difference between the actual data obtained and the PRESFLO model data expected. The R2 for the regression model is also very similar to its PRESFLO model, which means that modeling is better than regression because neural networks learn from experience and understand data patterns, whereas regression assumes that there is some (usually linear) relationship in the data and then checks to see if the data satisfies the assumption.

\section{Conclusion}

The main conclusions that can be taken from the current study is as follows: -

- The relationship of speed-density seems to be most important for drivers who change their speeds according to the density of the traffic around them. In general, the flow-density relationship is the most useful since it unifies different theoretical ideas and provides relationships for traffic control activities.

- A significant effect of cross-section parameters of the urban roads on the speed-flow relationship can be anticipated.

- The posted speed limit has a significant effect on the speed-flow relationship on urban roads.

- Parameters that were considered that consideration by many research are sufficient to develop reasonable speed-flow models. 


\section{Compliance with ethical standards}

\section{Acknowledgments}

Praise be to Allah, his Majesty, and the prophet Mohammed (God's blessing and peace upon him), for enabling me to complete this work. Also, great thanks go to my family, especially my husband and my children for their supporting .

\section{Disclosure of conflict of interest}

The author whose name appears in this article has hereby agreed that there is no conflict of interest with any organization.

\section{References}

[1] Jaehyun P. Modeling of setting speed limits on urban and suburban roadways. PhD Thesis. University of South F1orida: Florida. 2003.

[2] Bassani M, Dalmazzo D, Marinelli G, Cirillo C. Transportation Research Part F: Traffic Psychology and Behaviour. 2014; 25(10).

[3] Eluru N, Chakour V, Chamberlain M, Miranda-Moreno LF. Accident Analysis and Prevention. 2013; 59(125).

[4] Dinh DD, Kubota H. International Association of Traffic and Safety Sciences (IATSS). 2013; 36: 115.

[5] Moses R, Metoi E. Evaluation of Free Flow Speeds on Interrupted Flow Facilities. Project No. BDK83 977-18. Florida Department of Transportation, Tallahassee: Florida. 2013.

[6] M Mutani G. Transportation Research Record. 2012; 2298(78).

[7] Pei X, Wong S, Li Y, Sze N. Journal of Transportation Engineering. 2012; 138(1188).

[8] Schueller H. Modeling Speeds and Accidents on Urban Streets. ICTIS First International Conference on Transportation Information and Safety, (2011) June 30-July 2; Wuhan, China.

[9] Agina MA. Analyses of traffic congestion in urban Sub-Sahara Africa: A case study of Lagos, Nigeria. PhD Thesis. Texas Southern University: Texas. 2007.

[10] Asma TA. Empirical models for estimating automobiles running speeds on urban streets. PhD Thesis. George Mason University: Virginia. 2007.

[11] June M. Operating speed models for low speed urban environments based on in-vehicle GPS data. PhD Thesis GeorgiaInstitute of Technology: Atlanta. 2006.

[12] Fitzpatrick K, Miaou S, Brewer M, Carlson P, WooldridgeMD. Journal of Transportation Engineering. 2005; 131(261).

[13] Fitzpatrick K, Carlson P, Brewer M, Wooldridge M. Transportation Research Record: Journal of the Transportation Research Board. 2001; 1751(18).

[14] Ortúzar J de D, Willumsen LG. Modelling transport. 4th Editio. Chichester: John Wiley \& Sons Ltd. 2011.

[15] Akçelik R. travel time function for transport planning purpose: Davidson's function, its time-dependent form and an alternative travel time function. Aust Road Res. 2000; 3: 49-59.

[16] Rao AM, Rao KR. Free speed modeling for urban arterials - A case study on Delhi. Period Polytech Transp Eng. 2015; 43: 111-9.

[17] United Nations. World Population Prospects: The 2015 Revision, Key Findings and Advance Tables. New York: 2015.

[18] Lum KM, Fan HSL, Lam SH, Olszewski P. Speed - Flow Modeling of Arterial Roads in Singapore. Transportation Engineering. 1998; 124(3): $213-222$.

[19] Soliman HAHM. Improved Speed - Flow Model for Uninterrupted Traffic Flow in Egypt. Internet Document. 2000.

[20] American Association of State Highway and Transportation Officials (AASHTO), A Policy on Geometric of Highways and Streets. Washington. D.C. 1994. 
[21] Hall FL. Traffic Stream Characterestics. Internet document. 2004.

[22] Mcshane W, Ross R. Traffic Engineering Prentice - Hall, Inc., Englewood Cliffs, N. J. 1990; 558.

[23] Gerlough DL, Huber MJ. Traffic Flow Theory. A monograph TRB Special Report 165. Transp. Res. Board. Washington. D. C. 1975.

[24] Khisty CJ, Lall BK. Transportation Engineering. 2nd Edition. International Edition. 1998.

[25] Transportation Research Board (TRB). Highway Capacity Manual. Special Report 209, Updated Edition, Washington, D. C. 1994.

[26] Abdul - Kareem AM. The Characteristics of Traffic Flow for Two Major Highways in Bagdad City. M.Sc. Thesis. Building and Construction Engineering Department, University of Technology. 1998.

[27] Box PC, Oppenlander JC. Manual of Traffic Engineering Studies. 4th Edition. Institute of Transportation Engineering (ITE). Arlington. 1976.

[28] Harwood DW, May AD, Anderson IB, Leiman L, Archilla AR. Capacity and Quality of Service of Two-Lane Highways. Final Report, NCHRP Project 3-55 (3), Midwest Research Institute, 1999.

[29] Garber NJ, Hoel LA. Traffic and Highway Engineering. 2nd Edition. 1997.

[30] Mcshane W, Ross R. Traffic Engineering Prentice - Hall, Inc., Englewood Cliffs, N. J. 1990.

[31] Transportation Research Board (TRB). Highway Capacity Manual. Washington, D. C. 2000.

[32] Pignataro LJ. Traffic Engineering. Theory and Practice. Englewood Cliffs, Prentice - Hall. Inc. 1973.

[33] Kadiyali LR. Traffic Engineering and Transport Planning." 4th Edition. Delhi, Khanna Publishers. 1991.

[34] Munawar A. Procedia -Social and Behavioral Sciences. 2010; 16(382).

[35] Bhuyan PK, Krishna Rao KV. European Transport /Trasporti Europei. 2012; 49(38).

[36] Gerlough DL, Huber MJ. Traffic Flow Theory. A monograph TRB Special Report 165. Transp. Res. Board. Washington. D. C. 1975.

[37] Salter RL. Highway Traffic Analysis and Design. 2nd Edition, Hong Kong. 1989.

[38] Casey PW, Tindall JI. The Effect of the Directional Distributions on the Capacity of Two-Lane Two-Way Roads. Proceeding 3rd Australian Road Research Board Conference. 1966; 3(1).

[39] O'flaherty CA. Highways and traffic. Vol. 1 2nd Edition. London, Arnold. 1974.

[40] Duncan NC. Rural Speed / Flow Relations. Transport Road Research Laboratory, Report LR651, Crowthorne. 1974.

[41] Transportation Research Board, Highway Capacity Manual, Special Report 209. National Research Council, Washington, D.C. 1985.

[42] Schofield M. Speed-Flow and Capacity on the M6 Motorway. Traffic Engineering and Control. 1986; 27(10).

[43] Lewis PA. The Interpretation and Use of Speed, Flow Relationships for Transport Planners. Traffic Engineering and Control. 1990; 21(6): $304-309$.

[44] Brilon W, Weiser F. Capacity and Speed-Flow Relationships on Rural Two-Lane Highways. Proceedings of the Third International Symposium on Highway Capacity. 1998; 1.

[45] Luttinen RT. Level of Service on Finish Two-Lane Highways. Fourth International Symposium on Highway Capacity Proceedings, Transportation Research Circular E-C018, Transportation Research Board, Washington, D.C. 2000.

[46] Luttinen RT. Traffic Flow on Two-Lane Highways-An Overview. TL Research Report 1/2001, TL Consulting Engineers, Ltd., Lahti. 2001.

[47] Bang KL, Carlsson A, Palgunadi. Development of Speed Flow Relationship for Indonesia Rural Road using Empirical Data and Simulation. Transportation Research Record, No. 1484, Transportation Research Board, Washington, D. C. 1995.

[48] Hasan MJF. Spot Speed Characteristics of Erbil-Kirkuk Rural Highway. M.Sc. Thesis, College of Engineering, University of Salahaddin. 1989. 
[49] Malaysian Highway Capacity Manual, MHCM. Malaysia Highway Planning Unit, Ministry of Works: Kuala Lumpur. 2006.

[50] Tareq M. Al-Bahr, Othman Che Puan. speed-flow relationship for urban roads : a preliminary assessment. Research article . Advanced Science Letters. 2017.

[51] Hashim Samir Shafeek. Prediction Of Speed-Flow For Baghdad Urban Area Using Neural Network Approach . Ph. Thesis. transportation Engineering Department, Al- Mustansiriya University. 2006. 